\title{
TRÊS EPIGRAMAS DE CALÍMACO
}

Douglas Cristiano Silva*

O epigrama (de epígramma, substantivo derivado de epigráphein, "escrever sobre" ou simplesmente "inscrever") parece ter sido transmitido com o próprio alfabeto pelos fenícios aos gregos, por volta do século VIII a.C.

Por ter a princípio a função de ser o espaço de apresentação de decretos e homenagens e por possuir uma diferença fundamental em relação aos gêneros já estabelecidos da literatura grega (é um gênero que nasce escrito, ou seja, não corresponde à noção coletiva e performática da poesia grega anterior), o epigrama é visto por muito tempo como um espécie de artesanato, de arte menor. Somente com a transposição da poesia oral grega para o texto escrito uma outra *dsilva1988@gmail.com

Mestrando em Estudos Clássicos pelo Pós-Lit/UFMG.

visão sobre o gênero surge: o desenvolvimento paralelo de uma cultura literária de fato letrada confere ao epigrama, enfim, prestígio.

É no período helenístico ( 323-30 a.C.) que o gênero encontra sua definitiva inserção na poesia em língua grega. Sua concisão e simplicidade parecem se adequar perfeitamente aos ideais estéticos de alguns dos poetas da época que tinham como balizas a elegância, a sutileza, a erudição e a brevidade. Calímaco de Cirene (310/305?-240 a.C.) é para boa parte dos comentadores uma espécie de arquétipo da noção de poeta de então, o poeta-scholar, e foi um dos grandes epigramatistas de seu período. Foram-nos transmitidos, inteiros, sessenta e 
três de seus epigramas, um corpus bastante significativo em quantidade e em variedade, especialmente se compararmos com a transmissão do restante de sua obra, que é, hoje, com exceção desses epigramas e de seis hinos e a despeito de sua importância na antiguidade, bastante fragmentada.

Os três epigramas a seguir apresentados são epigramas fúnebres, poemas que emulam a estrutura de epitáfios ou se relacionam de alguma outra forma com o tema da morte, com a presença da lápide. É possível notar mesmo nesse pequeno conjunto algumas características do gênero: há na sua existência a marca da tentativa de manutenção da presença da material daquele que é representado, sabendo aquele que inscreve que a materialidade da pedra (e, mais tarde, do texto - copiado, imitado, citado, recolhido) resiste mais do que o corpo humano, presente ou ausente, sob a tumba; o gênero carrega em si a força formular que o epigrama fúnebre trasmite - " $\mathrm{X}$, filho de $\mathrm{Y}$, nascido em Z" -, e o afastamento desse padrão (como ocorre nos epigrama apresentados) é altamente significativo; há, ainda um intenso jogo de enunciação que surge do afastamento do poema em relação ao objeto ao qual necessariamente estaria ligado caso não estivesse em contexto literário. Sem esse objeto como referência não é possível saber de antemão a que se dirige a forma dêitica do epigrama nem quem são o emissor e o destinatário de sua mensagem.
O primeiro epigrama, 13 Pf., é um curioso e revelador diálogo entre passante, lápide e morto. É notável que aqui não haja qualquer tentativa de imitar a estrutura de um epitáfio, somente a apropriação do contexto fúnebre e da comunicação momentânea que se dá entre a lápide e passante. É notável, ainda, a irreverência do poeta em relação à possibilidade de "reencarnações" e a Plutão, nome romano de Hades, senhor do mundo dos mortos (Cáridas utiliza as palavras pseũdos e mỹthos para descrevê-los, respectivamente). Não há, por fim, qualquer preocupação em relação à apresentação de personagens ou transições de enunciação: todos esses problemas surgem e são resolvidos na própria brevidade da leitura, no caráter necessariamente sintético de sua apresentação.

O epigrama seguinte também não emula a estrutura de um epitáfio, mas carrega em si, na formação de um clímax, a estrutura imaginária de um, como uma sombra: o passante nos apresenta primeiramente o nome da morta, tradicionalmente a primeira das informações. Acompanhamos então, passo a passo, suas reações à leitura do texto gravado na lápide: a dúvida ("mas quem és?"), a pausa reflexiva, que parece indicar um tempo de leitura, a surpresa ("Pelos deuses!") e a lamentação em relação ao viúvo. $\mathrm{Na}$ leitura do passante encontramos um possível epitáfrio, enfim: "Timônoe de Metina, filha de Timóteo”. 
Por fim, o epigrama 18 Pf. Sendo a Hélade continente e arquipélago, um país aberto para o Mediterrâneo, é de se imaginar que o mar seria uma figura constante no imaginário da poesia grega. A morte por água, em especial, de Arquíloco a Calímaco, faz parte desse imaginário, é um tópos poético. $\mathrm{O}$ epitáfio de um morto por naufrágio traz necessariamente a ausência de um corpo, no nosso caso lamentada não só pelos entes queridos, mas também pelo próprio túmulo, que ainda aconselha aqueles que por ele passarem a não cometer o mesmo erro do morto, que, apesar de morto, não está lá.

$* * *$

\section{PF.}

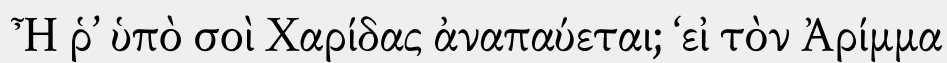

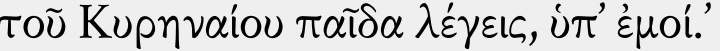

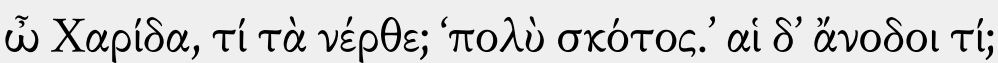

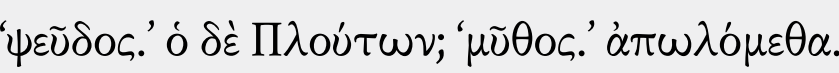

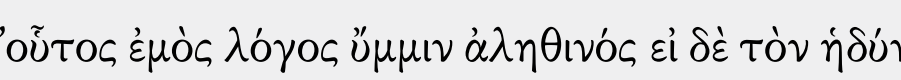

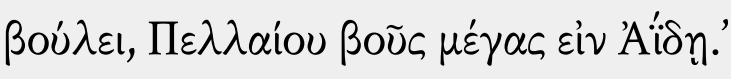

Acaso é sob ti que jaz Cáridas? "Se do filho de Arima de Cirene falas, é sob mim mesmo".

Ô, Cáridas! O que há aí embaixo? "Muita treva”. E quanto à volta? "Mentira”. E Plutão? "História”. Estamos perdidos!

"Isto que vos direi é verdade: se o deleite

queres, a moeda com um boi vale um boi de verdade no Hades".

\section{COMENTÁRIOS À TRADUÇÃO}

v. 3: "E quanto à volta?" (no original um plural, "às voltas”) - a palavra em grego, ánodoi, é a junção do prefixo aná, no caso algo como "de volta", e da palavra hódos, "estrada, caminho”. Refere-se à suposição de que a alma voltaria a seu estado original após a morte.
1. O texto grego dos três epigramas segue fielmente edição de Pfeiffer: Callimachus. Ed. R. Pfeiffer. Oxford: Oxford Clarendon Press, 1953. 
v. 6: Um trecho de difícil tradução. Literalmente: "um grande boi [custa] um pelaio no Hades". Alguns comentadores afirmam que "pelaio" se refere a uma moeda de Pela que possuía pouco valor. Partindo da proverbial noção antiga de que o Hades é um local de baixo custo de vida, há um claro jogo entre o boi da moeda e o grande boi que poderia ser por ela comprado.

\section{PF.}

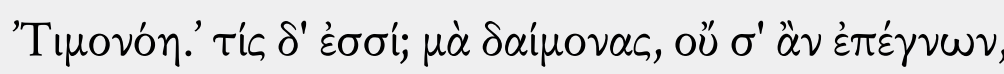

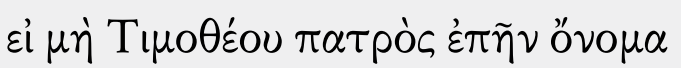

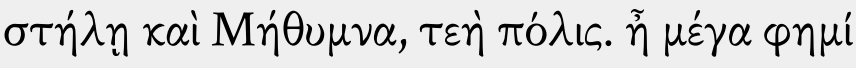

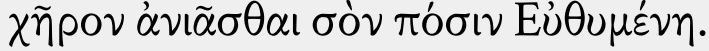

“Timônoe". Mas quem és? Pelos deuses!, não te reconheceria se de Timóteo, teu pai, o nome não houvesse

na pedra, e a cidade, Metimna. Ah! Grande, sei,

é o sofrer do viúvo, teu marido Eutímenes.

\section{COMENTÁRIOS À TRADUÇÃO}

v.1: "Pelos deuses!" - no original, daímonas. Daímōn é o termo usado para se referir a uma divindade de modo genérico.

"Não te reconheceria..." - A partir do uso do verbo epigignōskō acredita-se que poderia haver no túmulo um retrato de Timônoe.

\section{$18 \mathrm{PF}$.}

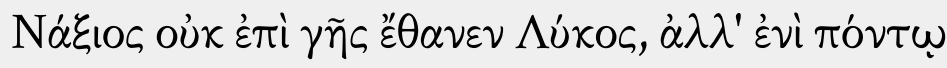

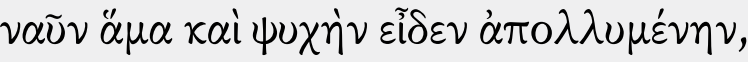

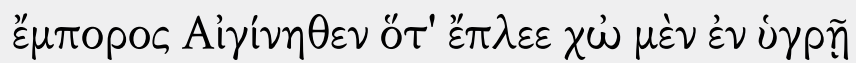

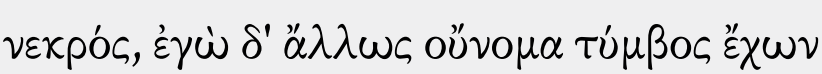

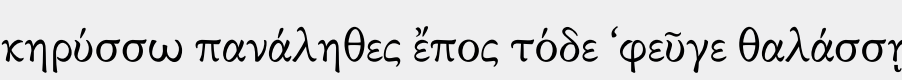

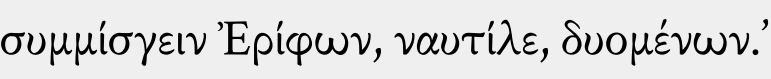

Não foi em terra que Lico, o náxio, morreu. No mar o mercador viu nau e vida ao mesmo tempo

se perderem quando de Egina navegava. Ele, na água,

um corpo; eu, lápide, não passo de um nome

e proclamo esta tão verdadeira sentença: "Evita com o mar

se encontrar, navegante, quando se põem os Érifos”.

COMENTÁRIOS À TRADUÇÃO

v. 3 e 4: "Ele na água, / um corpo; eu, lápide [...]”. No texto grego, há um jogo bastante significativo de partículas intraduzíveis da língua grega (mèn e dè), partículas que sugerem contraposição. A simples parataxe me parece suficiente. 
v. 6: Érifos - Em tradução, "os Cabritos". Duas estrelas que fazem parte da constelação do Auriga (ou Cocheiro).

Desaparecem do campo de visão no Hemisfério Norte no

início do inverno, anunciando o início de uma temporada

ruim para a navegação. 